\title{
KAJIAN PERKEMBANGAN TEKNOLOGI SENSOR GAS UNTUK EMISI GAS BUANG KENDARAAN BERMOTOR
}

\author{
Slamet Widodo \\ Pusat Penelitian Elektronika dan Telekomunikasi, \\ Lembaga Ilmu Pengetahuan Indonesia (PPET-LIPI) \\ E-mail: slametwidodo50@gmail.com
}

\begin{abstract}
ABSTRAK
Sensor gas berbasis metal oksida telah banyak digunakan untuk mendeteksi gas-gas polutan yang dihasilkan dan emisi gas buang kendaraan bermotor, seperti $\mathrm{CO}, \mathrm{SO}_{2}, \mathrm{NH}_{3}, \mathrm{NO}$, hidrokarbon (HC), dsb. Akan tetapi permasalahan yang sampai sekarang masih dihadapi oleh sensor gas berbasis metal oksida adalah rendahnya sensitivitas, lemahnya selektivitas, dan kurangnya stabilitas sensor. Oleh karena itu, sangat sulit untuk menghasilkan sebuah sensor gas berbasis metal-oksida yang akurat dan bertahan untuk jangka waktu yang lama. Dalam review yang singkat ini, akan dibahas state-of-the-art teknologi, metode rancang bangun, dan teknik-teknik yang dapat dilakukan dalam meningkatkan kinerja sensor gas berbasis metal oksida.
\end{abstract}

Kata kunci : pencemaran udara, emisi kendaraan bermotor, sensor gas, metal oksida

\section{PENDAHULUAN}

Polusi udara menimbulkan berbagai dampak negatif baik pada manusia, makhluk hidup lain maupun lingkungan. Apa saja dampak yang ditimbulkan akibat polusi udara? [1]. Terutama dalam dunia otomotif, monitoring kualitas udara sangat penting dilakukan karena beberapa hal pertama, emisi gas buang kendaraan bermotor merupakan sumber utama (kurang lebih 70\%) pencemaran udara di Indonesia.

Kondisi ini tentunya sangat membahayakan kesehatan manusia dan berpotensi merusak lingkungan. Kedua, udara luar diperlukan sebagai input dalam sistem air conditioning (AC) mobil-mobil terbaru. Rendahnya kualitas udara luar akibat polusi akan mengganggu kenyamanan penumpang dalam kabin. Ketiga, sistem mesin diesel moderen berkerja dengan rasio air-to-fuel (A/F) tinggi, sehingga menimbulkan ekses oksigen dalam sistem exhaust dan berakibat pada timbulnya gas (beracun) NOx dalam konsentrasi tinggi.

Teknik monitoring pencemaran udara dapat dilakukan menggunakan sensor gas yang diletakkan dalam saluran exhaust kendaraan bermotor, atau dengan pemantauan kualitas udara luar secara langsung. Walaupun keduanya membutuhkan sensor dengan spesisifikasi yang berbeda, namun tetap harus memiliki sensitifitas tinggi agar mampu mendeteksi gasgas polutan dengan konsentrasi dibawah ambang batas minimum. Selain itu, sensor gas tersebut juga harus selektif, yaitu dapat mendeteksi jenis gas tertentu diantara beberapa campuran gas. Dalam beberapa tahun terakhir, jenis sensor gas yang digunakan untuk 
mendeteksi polutan telah dibuat dengan mekanisme pendeteksian yang didasarkan pada sifat-sifat optik, kapasitansi, mass-sensitive, konduksi ion, kalorimeter, dan resistivitas dari material yang digunakan. Diantara jenis-jenis tersebut, yang paling banyak digunakan adalah sensor gas dengan prinsip perubahan resistivitas menggunakan bahan metal oksida, seperti $\mathrm{SnO}_{2}$, $\mathrm{WO}_{3}, \mathrm{In}_{2} \mathrm{O}_{3}, \mathrm{ZnO}$, dsb. [2-5]. Sensor gas berbasis metal oksida memiliki keunggulan dalam hal rendahnya biaya fabrikasi, kesederhanaan prinsip pengoperasiaannya, memiliki daya tahan yang bagus serta mudah dalam pemeliharaannya [6]. Namun kelemahan utama dari sensor gas ini terletak pada selektifitasnya yang rendah.

Oleh karena itu, dalam tulisan ini akan dibahas state-of-the art teknologi, metode rancang bangun, dan teknik-teknik yang dapat dilakukan untuk meningkatkan kinerja sensor gas berbasis metal oksida melalui modifikasi struktur material. Review ini merupakan bagian dari penelitian rancang bangun sensor gas berbasis metal oksida yang sedang kami lakukan di Pusat Penelitian Elektronika dan Telekomunikasi, dan ditujukan dalam rangka mendapatkan metode rancang bangun yang aplikatif dan menghasilkan divais sensor dengan spesifikasi yang optimum.

\section{TINJAUAN PUSTAKA}

State-of-the-art teknologi tentang penelitian sensor gas berbasis metal oksida sebetulnya telah dilakukan sejak tahun 1960 an, yang diawali oleh Seiyama [7]. Akan tetapi, secara komersial baru dapat diproduksi pada tahun 1970 oleh Taguchi. Sensor Taguchi terbuat dari filamen heater dan elektroda dari bahan emas yang dibungkus dengan lapisan sensitif gas dari bahan $\mathrm{SnO}_{2}$. Walaupun sampai sekarang sensor Taguchi masih banyak tersedia di pasaran, namun teknologi fabrikasinya yang bersifat konvensional membuat konsumsi dayanya tinggi, sekitar 3-5 W [8].

Oleh karena itu, orang mulai menggunakan teknik screen-printing dalam fabrikasi sensor gas berbasis metal oksida. Dengan screenprinting, elemen heater, elektroda, dan bahan sensitif gas dari metal oksida dapat dilapiskan diatas substrat alumina dengan ukuran yang lebih kecil, sehingga konsumsi dayanya dapat diturunkan menjadi sekitar $200 \mathrm{~mW}-1 \mathrm{~W}$ [9]. Keuntungan lain dari digunakannya teknik screen-printing adalah memungkinkan sensor diproduksi dalam jumlah banyak secara serentak, sehingga mengurangi biaya fabrikasi per sensornya.

1. Seiring dengan perkembangan teknologi proses semikonduktor dan kebutuhan akan divais yang bersifat portabel, dewasa ini banyak sensor gas yang telah difabrikasi dengan teknik micromachining. Selain dimensinya menjadi jauh lebih kecil dibandingkan dengan screen-printing, teknik micromaching

(MEMs) memungkinkan sensor gas dibuat diatas 
membran tipis untuk mengisolasi panas yang dihasilkan oleh elemen heater. Dengan cara ini, konsumsi daya dapat ditekan lebih rendah lagi hingga sekitar 3 -
$150 \mathrm{~mW}$ [10]. Dalam Gambar-1 dapat dilihat tipikal sensor gas dengan teknologi MEMs diatas silikon.

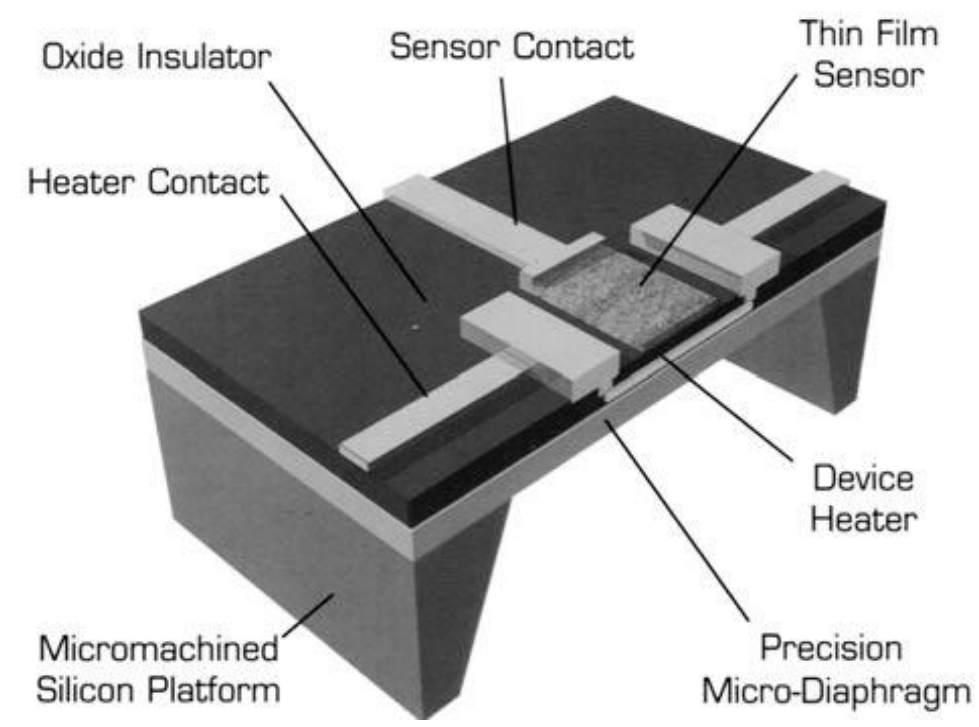

Gambar-1. Tipikal struktur sensor gas yang difabrikasi menggunakan teknologi MEMs diatas substrat silikon. Dimensi divais seperti ini hanya beberapa $\mathrm{mm}^{2}$ dengan konsumsi daya dalam orde $\mathrm{mW}$ [11].

\section{METODE}

Metode rancang bangun sampai saat ini, teknik yang digunakan dalam fabrikasi divais sensor gas dapat dikategorikan dalam dua teknologi, yaitu thick-film dan thin-film. Dalam teknologi thick-film, proses fabrikasi divais terdiri dari beberapa tahapan sederhana dan diulang sesuai dengan jenis dan jumlah lapisan yang digunakan. Dalam Gambar-2 dapat dilihat alur tahapan proses yang umum digunakan dalam fabrikasi sensor gas menggunakan teknologi thick-film. Inti dari teknologi thick-film adalah proses screen-printing menggunakan pasta untuk membentuk lapisan-lapisan yang menjadi elemen dari sensor. Kebanyakan proses screen-printing menggunakan substrat dari alumina $\left(\mathrm{Al}_{2} \mathrm{O}_{3}\right)$, dan ketebalan lapisan yang dihasilkan antara $8-25 \mu \mathrm{m}$. Pembuatan sensor gas dengan proses teknologi thick-film ada 9 tahapan seperti berikut ini, 


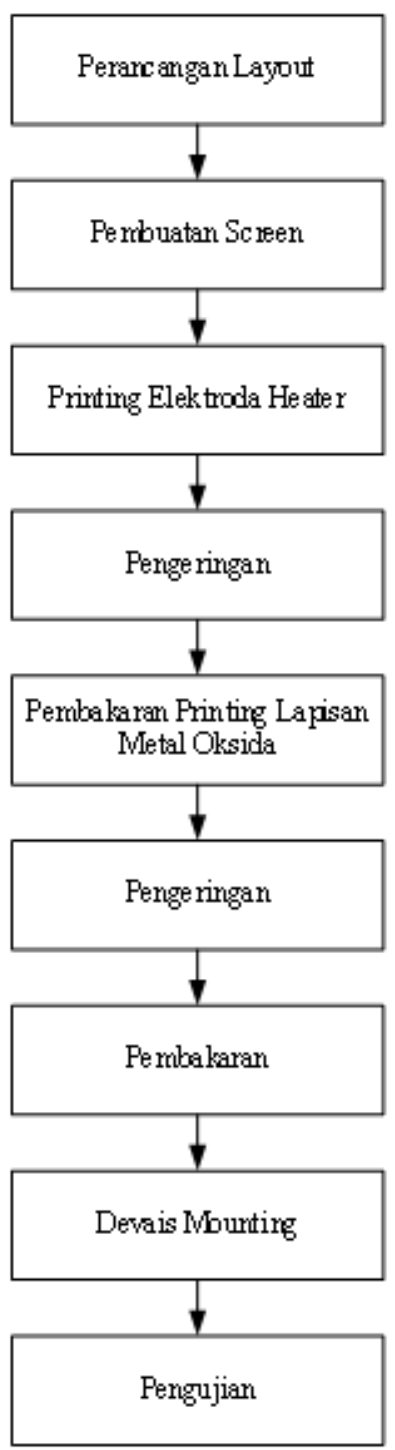

\section{Gambar-2. Tahapan proses fabrikasi sensor gas menggunakan teknologi thick-film}

Teknologi thin-film, dilain pihak, menghasilkan lapisan dengan ketebalan hanya beberapa mikro meter $(1-2 \mu \mathrm{m})$. Hal ini disebabkan karena lapisan yang ditumbuhkan diatas substrat melalui proses metalisasi ( menggunakan sputtering atau evaporasi), terjadi melalui level atomik atau molekul. Dengan begitu, karakteristik lapisan thin- film berbeda dengan thick-film. Dalam Gambar 3 dapat dilihat alur proses fabrikasi sensor gas menggunakan teknologi thin-film. Teknologi thinfilm bisa menggunakan substrat silikon atau alumina. Pembuatan sensor gas dengan proses teknologi thin-film ada 8 tahapan : 


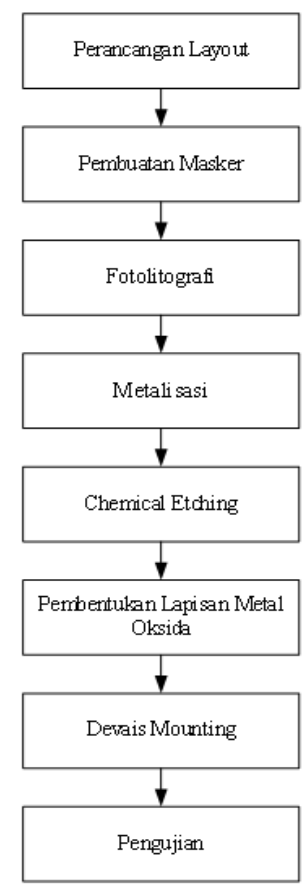

Gambar 3. Tahapan proses fabrikasi sensor gas menggunakan teknologi thin-film

Yang sering terjadi adalah kombinasi antara teknologi thick-film dan thin-film. Sebagai contoh, dalam pembentukan lapisan metal oksida, bahan $\mathrm{SnO}_{2}$ dalam bentuk pasta dapat di screen-printing diatas elektroda thin-film dengan substrat silikon [12].

\section{HASIL DAN PEMBAHASAN}

\section{Teknik Meningkatkan Kinerja Sensor}

Untuk mendapatkan sensor gas berbasis metal oksida yang akurat, ada tiga parameter yang harus ditingkatkan, yaitu sensitivitas, selektivitas, dan stabilitas dari sensor tersebut.

\section{Sensitivitas}

Sensitivits adalah kemampuan dari sensor dalam mempersiapkan perubahan sifat-sifat fisik atau kimiawi dari lapisan metal oksida ketika berinteraksi dengan gas. Untuk tiap konsentrasi gas yang dideteksi, sensitivitas didefini sebagai

$$
\mathrm{S}=(\mathrm{Rg}-\mathrm{Ra}) / \mathrm{Ra} \times 100 \%
$$

Dimana $\mathrm{Rg}$ adalah resistansi sensor dalam konsentrasi gas saat pengukuran dan $\mathrm{Ra}$ resistansi sensor di udara. Agar sensitivitas sensor dapat maksimal, maka harus digunakan jenis material metal oksida yang paling sesuai dengan gas yang akan dideteksi, dan sensor dioperasikan dengan temperatur yang optimum. Oleh karena itu, karakterisasi terhadap sensitivitas harus dilakukann pada seluruh cakupann temperatur kerja sensor, sehingga bisa ditentukan temperatur optimumnya. 
Sedangkan untuk meningkatkann sensitivitas material terhadap gas yang dideteksi dapat dilakukann dengan penggunaan metal oksida jenis baru yang lebih sensitif, penggunaan material dengan struktur nano, penggunaan bahan katalis/doping, serta penggunaan teknologi baru untuk menumbuhkan material.

\subsection{Material metal oksida dengan struktur nano}

Penggunaan materiall dengan struktur nano akan memberikan total luas permukaan yang lebih tinggi terhadap gas. Karena mekanisme interaksi antara sensor dengan gas hanya terjdi di permukaan dari butiran partikel metal oksida, maka penggunaan material nano jelas akan meningkatkan sensitivitas sensor [13]. Teknik yang banyak digunakan untuk menghasilkan materal metal oksida dalam struktur nano adalah melalui proses sol-gel, sputtering, atau milling [14].

Dalam proses sol-gel, senyawa klorit yang berisi metal seperti $\mathrm{Sn}$, Ti atau In, direaksikan dengan ammonium hidroksida untuk mendapatkan endapan metal hidroksida (sol). Setelah dikeringkan dengan temperatur sekitar $60{ }^{0} \mathrm{C}$, akan dihasilkan gel yang kemudian dikalsinasi untuk mendapatkan material dalam fasa nano. Secara umum proses sol-gel untuk mendapatkan $\mathrm{SnO}_{2}$ dapat dituliskan sebagai berikut,
$\mathrm{SnCl}_{4}+4 \mathrm{NH}_{4} \mathrm{OH} \rightarrow \mathrm{Sn}(\mathrm{OH})_{4}+4 \mathrm{NH}_{4} \mathrm{Cl} \ldots$ (2)

Dewasa ini, proses sputtering mulai banyak digunakan untuk membentuk lapisan metal oksida. Walaupun struktur dari metal oksida yang dilapiskan tergantung pada jenis substrat, tetapi menggunakan proses sputtering ketebalan lapisan metal oksida dapat dikendalikan dengan lebih akurat. Sensitivitas sensor akan meningkat dengan penggunaan lapisan metal oksida yang semakin tipis [15].

Proses mekanik seperti planetary-ball-mill dapat digunakan untuk menghasilkan partikel berukuran nanometer dari serbuk metal oksida [16]. Ukuran partikel yang dihasilkan sangat ditentukan oleh kecepatan rotasi dan waktu yang digunakan, tetapi umumnya berkisar antara $20-30 \mathrm{~nm}$.

\subsection{Peran katalis / doping}

Beberapa penelitian telah menunjukkan bahwa penambahan aditif, baik dari bahan logam mulia ( $\mathrm{Pt}, \mathrm{Pd}, \mathrm{Au}, \mathrm{Ag}$ ) maupun metal oksida transisi, dapat meningkatkan sensitivitas material metal oksida terhadap gas-gas tertentu [17]. Seperti ditunjukkan dalam Gambar 4, unsur-unsur aditif ini dapat merubah sifat-sifat dari metal oksida utama, seperti porositas, stoikiometri, komposisi fase, komposisi elemen, konsentrasi pembawa muatan bebas, ukuran partikel, dan arsitektur permukaan. Oleh karena itu, selain meningkatkan sensivitas, penambahan adititif juga dapat meningkatkan selektivitas dan 
ISSN 1979-4835

E-ISSN 2721-2335

response-time, serta menurunkan temperatur kerja sensor. proses pembentukannya, dengan komposisi kurang dari $5 \%$ berat.

Aditif biasanya berupa doping yang

dicampurkan dengan material dasar pada saat

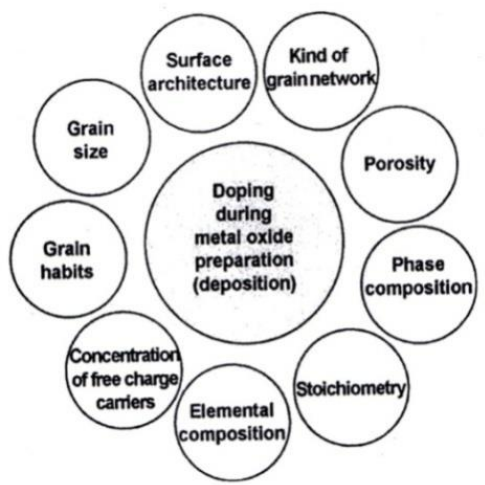

Gambar-4 Parameter yang dapat berubah karena doping pada saat pembentukan material metal oksida[18]

\section{Selektivitas}

Selektevitas adalah kemampuan sensor dalam membedakan gas yang satu diantara campuran beberapa gas. Sebagaimana diketahui, sensor gas berbasis metal oksida, kemungkinan bisa terjadi bahwa jenis gas dan konsentrasi yang berbeda bisa menghasilkan nilai konduktivitas yang hampir sama.
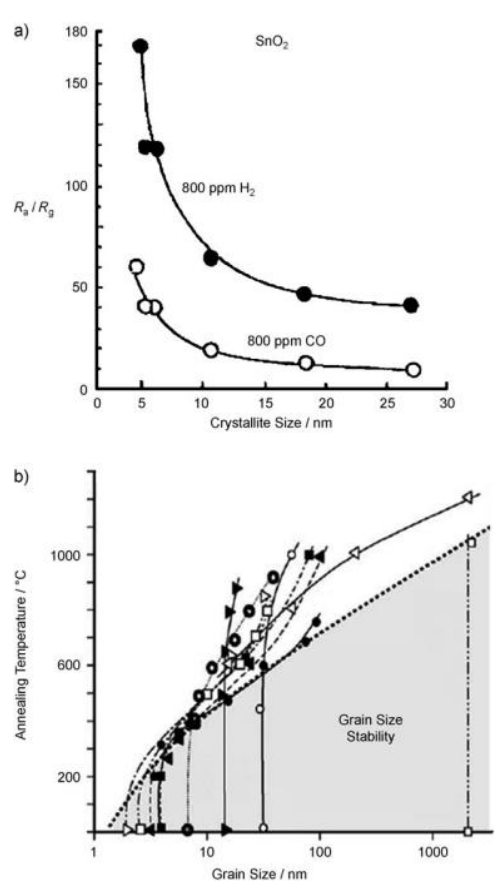


\section{Gambar 5. Pengaruh selektivitas sensor gas hidrogen terhadap CO [19]}

Hal ini disebabkan karena selektivitas sensor adalah parameter yang tergantung pada banyak faktor seperti penyerapan gas di permukaan sensor, reaksi kinetik, dan perpindahan elektron dari dan ke pita konduksi dari bahan semikonduktor. Dalam Gambar 5 dicontohkan selektivitas sensor gas $\mathrm{H}_{2}$ terhadap CO.

Untuk mengatasi hal itu, metode yang dapat dilakukan adalah dengan membuat sensor array, dimana dalam satu divais terdapat dua atau lebih lapisan metal oksida, dengan masingmasing memiliki sensitivitas yang berbeda-beda terhadap gas dalam campuran. Sinyal yang dihasilkan oleh masing-masing sensor kemudian dapat diolah menggunakan semacam jaringan syaraf (neural network) [18]. Metode ini dikenall dengan istilah hidung elektronik ( $e$ nose), dan telah banyak diterapkan untuk mendeteksi aroma yang dihasilkan oleh makanan, minuman, kosmetik, dan pencemaran lingkungan [20].

Keberhasilan e-nose tidak hanya tergantung pada teknologi fabrikasi divais sensor, tetapi juga pada tersedianya perangkat lunak untuk rekognisi pattern yang handal. Selain itu, hal yang perlu diperhatikan adalah meningkatnya kompleksitas sistem, biaya, ukuran, dan portabilitasnya.

\section{Stabilitas}

Stabilitas sensor adalah kemampuan mempertahankan hasil pengukuran setelah pemakaian untuk jangka waktu yang lama. Kenyataan yang tidak bisa dihindarii adalah terjadinya perubahann sifat secara perlahan terhadap material metal oksida akibat perubahan temperatur dan atmosfir lingkungan. Perubahan ini disebut drift, dan pengaruhnya adalah penurunan sensitivitas sensor terhadap gas-gas dengan konsentrasi rendah. Drift bisa dikurangi dengan proses kalsinasi terhadap material metal oksida dengan temperatur antara $400-1000{ }^{\circ} \mathrm{C}$ selama $1-8$ jam sebelum sensor digunakan [18].

\section{KESIMPULAN}

Dalam tulisan ini, telah dibahas state-of-the-art teknologi, metode rancang bangun, dan teknikteknik yang dapat dilakukan dalam meningkatkan tiga parameter kinerja sensor gas berbasis metal oksida, yaitu sensitivitas, selektivitas, dan stabilitas. Sesuai dengan trend perkembangannya, sensor gas berbasis metal oksida masih akan menjadi subjek menarik dalam penelitian di masa-masa yang akan datang. Selain karena aplikasinya yang makin luas, juga ditunjang oleh perkembangan teknik sintesa dan modifikasi struktur material dalam level nano, yang memungkinkan terjadinya peningkatkan kualitas metal oksida yang 
dihasilkan. Selain itu, adanya teknik pengolahan sinyal yang mampu memetakan hasil analisa dari sistem multi-sensor juga sangat penting fungsinya untuk mengatasi masalah selektivitas sensor.

\section{DAFTAR PUSTAKA}

[1] Arum Sutrisni Putri, "Pencemaran Udara: Dampak dan

Solusi", https://www.kompas.com/skola /read/2020/01/17/140000269/pencemara n-udara--dampak-dan-solusi.

[2] Suzuki, T., Kunihara, K., Kobayashi, M., Tabata, S., Higaki, K. \& Ohnishi, H., 'A micromachined gas sensor based on a catalytic thick film $/ \mathrm{SnO}_{2}$ thin film bilayer and thin film heater Part $1: \mathrm{CH}_{4}$ sensing', Sensors and Actuators B, vol. 109, 2005, pp. 185-189.

[3] Barsan, N., Stetter, J. R., Findlay, Jr., M. \& Gopel, W.,'High-performance gas sensing of CO: comparative tests for semiconducting $\left(\mathrm{SnO}_{2}\right.$-ased) and for amperometric gas sensors', Analytical Chemistry, vol. 71, 1999, pp. 2512 2517.

[4] Tang, H., et al., ' $\mathrm{TiO}_{2}$ anatase thin films as gas sensors', Sensors and Actuators B, vol. 26-27, 1995, pp. 71-75.

[5] Arshak, K. \& Gaidan, I., 'Gas sensing properies of $\mathrm{ZnFe}_{2} \mathrm{O}_{4} / \mathrm{ZnO}$ screenprinted thick films', Sensors and Actuators B, vol. 111-112, 2005, pp.5862.

[6] Moseley, P.T., 'Thick-film semicondutor gas sensors', in Thick Film Sensors, ed. M. Prudenziati, Elsevier Science, Amsterdam, 1994, pp. 289-311.

[7] Seiyama, T., Kato, A., Fujushi, K., \& Nagatani, M., 'A new detector for gaseous components using semiconductive thin films', Analytical Chemistry, vol. 34, 1962, p. 1502f.

[8] Taguchi, N., Japanese Patent 47-38840.
[9] Williams, G. \& Coles, G. S. V., 'Micropowered gas sensors using thick and thin films of semiconducting oxide', Sensors and Their Applications VIII, IOP Publishing, 1997, pp. 219-224.

[10] Fung, S. K. H.., Tang, Z., Cheung, P. W., 'Thermal analysis and design of a micro-hotplate for integrated gas-sensor applications', Sensors and Actuators A, vol. 54, 1996, pp. 482-487.

[11] Kohl, D., 'Function and applications of gas sensors', Journal of Physics D: Applied Physics, vol. 34, 2001, pp. R125-R149.

[12] Tabata, S., Higaki, K., Ohnishi, H., Suzuki, T., Kunihara, K. \& Kobayashi, M., 'A micromachined gas sensor ased on a catalytic thick film / $\mathrm{SnO}_{2}$ thin film bilayer and thin film heater Part 2 : CO sensing', Sensors and Actuators B, Vol. 109, 2005, pp. 190 - 193.

[13] Baraton, M. I. \& Merhari, L., 'Electrical behavior of semiconducting nanopowders versus environment', Review of Advance Material Science, vol.4, 2003, pp. 15-24.

[14] Mochida, T., Kikuchi, K., Kondo, T., Uono, H. \& Matsuura, Y., 'Highly sensitive and selective $\mathrm{H}_{2} \mathrm{~S}$ gas sensor from r.f. sputtered $\mathrm{SnO}_{2}$ thin film', Sensors and Actuators B, vol. 24-25, 1995, pp. 433-437.

[15] Ivanov, P., Llobet, E., Vergara, A., Stankova, M., Vilanova, X., Hubalek, J., Gracia, I., Cane, C. \& Correig, X., 'Towards a micro-system for monitoring ethylene in warehouses', Sensors and Actuators B, vol. 111-112, 2005, pp. 6370.

[16] Kersen, U., 'The gas-sensing potential of nanocrystalline $\mathrm{SnO}_{2}$ produced by a mechanochemical milling via centrifugal action', Applied Physics A: Material Science \& Processing, vol. 75, 2002, pp. 559-563.

[17] Nanto, H., Kawai, T. \& Tsubakino, S., ' $\mathrm{ZnO}$ thin film chemical sensor for trimethyl- and dimethylamine gases', Proceedings Symposium on Chemical Sensor II (Pennington, NJ, USA) Sensor 
ISSN 1979-4835

E-ISSN 2721-2335

Group Proc. Vol 93-97, ed M Buttler, A Ricco and N Yamazoe (The Electrochemical Society Inc.), 1993, pp. 522-525.

[18] Korotcenkov, 'Gas response control through structural and chemicall modification of metal oxide films: state of the art and approaches', Sensors and Actuators B, vol. 107, 2005, pp. 209232.
[19] A.Tricoli, A. Teleki and M. Righettoni, Review of Semiconductor Gas Sensor: Dry Synthesis and Application, Angewandte Chemie, 2010, Vol.49, pp. 7632-7659.

[20] Cosandey, F., Skandan, G. \& Singhal, A., 'Materials and processing issues in nanostructured semiconductor gas sensors', JOM-e 52 (10), 2000. 